\title{
Splenic vein stenting for recurrent chylous ascites in sinistral portal hypertension: a case report
}

\author{
Brian Covello* ${ }^{*}$, Jacob Miller and Roberto Fourzali
}

\begin{abstract}
Background: Sinistral portal hypertension results from obstruction or stenosis of the splenic vein and is characterized by normal portal vein pressures and liver function tests. Gastrointestinal bleeding is the most common presentation and indication for treatment. Although sinistral portal hypertension-related chylous ascites is rare, several cases have described successful treatment with portal venous, rather than splenic venous, recanalization. Splenectomy is effective in the treatment of sinistral portal hypertension-related bleeding, although recent studies have evaluated splenic vein stenting and splenic arterial embolization as minimally-invasive treatment alternatives. Splenic vein stenting may be a viable option for other presentations of sinistral portal hypertension.

Case presentation: A 59-year-old gentleman with a history of necrotizing gallstone pancreatitis was referred to interventional radiology for management of recurrent chylous ascites. Analysis of ascites demonstrated a triglyceride level of $1294 \mathrm{mg} / \mathrm{dL}$. Computed tomography revealed splenic and superior mesenteric venous stricture. The patient elected to undergo minimally invasive transhepatic portal venography, which confirmed the presence of splenic vein and superior mesenteric vein stenosis. Venography of the splenic vein showed reversal of portal venous flow, multiple collaterals, and a pressure gradient of $14 \mathrm{mmHg}$. Two $10 \mathrm{~mm} \times 40 \mathrm{~mm}$ Cordis stents were placed, which decreased the pressure gradient to $7 \mathrm{mmHg}$ and resolved the portosystemic collaterals. At 6 months follow-up, the patient had no recurrent episodes of ascites.

Conclusion: The current case highlights the successful treatment of sinistral portal hypertension-related intractable chylous ascites treated with transhepatic splenic vein stenting. Splenic venous stent patency rates of $92.9 \%$ at 12 months have been reported. Rebleeding rates of $7.1 \%$ for splenic vein stenting, $16 \%$ for splenectomy, and $47.8 \%$ for splenic arterial embolization have been reported in the treatment of sinistral portal hypertension-related gastrointestinal bleeding. The literature regarding splenic vein stenting for sinistral portal hypertension-related ascites is less robust. Technical and clinical success in the current case suggests that splenic vein recanalization may be a safe and viable option in other sinistral portal hypertension-related symptomatology.

Level of Evidence: Level 4, Case Report.
\end{abstract}

Keywords: Sinistral portal hypertension, Splenic vein stenting, Splenic vein stenosis, Chylous ascites

\footnotetext{
* Correspondence: brcovello@gmail.com

Department of Radiology, Aventura Hospital \& Medical Center, 20900

Biscayne Blvd, Aventura, FL 33180, USA
}

\section{SpringerOpen}

(c) The Author(s). 2021 Open Access This article is licensed under a Creative Commons Attribution 4.0 International License, which permits use, sharing, adaptation, distribution and reproduction in any medium or format, as long as you give appropriate credit to the original author(s) and the source, provide a link to the Creative Commons licence, and indicate if changes were made. The images or other third party material in this article are included in the article's Creative Commons licence, unless indicated otherwise in a credit line to the material. If material is not included in the article's Creative Commons licence and your intended use is not permitted by statutory regulation or exceeds the permitted use, you will need to obtain permission directly from the copyright holder. To view a copy of this licence, visit http://creativecommons.org/licenses/by/4.0/. 


\section{Introduction}

Sinistral portal hypertension (SPH) results from obstruction or stenosis of the splenic vein and is characterized by normal portal vein pressures and liver function tests (El Kininy et al. 2017). Gastrointestinal bleeding (GIB) is the most common presentation and indication for treatment (El Kininy et al. 2017). Although SPH-related chylous ascites is rare, several cases describe successful treatment with portal venous recanalization (Tsauo et al. 2016; Poo et al. 2018; Maleux et al. 2003). Splenectomy is effective in the treatment of SPH-related GIB, although recent studies have evaluated splenic vein stenting (SVS) and splenic arterial embolization (SAE) as minimally-invasive treatment alternatives (Ghelfi et al. 2016; Luo et al. 2014; Stein and Link 1999; Wei et al. 2020). Herein, a case of SPH-related recurrent chylous ascites successfully treated with SVS is described.

\section{Case report}

IRB approval was not required by our institution for this case report. A 59-year-old gentleman with a history of necrotizing gallstone pancreatitis and atrial fibrillation was referred to interventional radiology for management of recurrent chylous ascites. The patient had gallstone pancreatitis 2 years prior to referral, which was complicated by the formation of recurrent and refractory infected pancreatic pseudocysts requiring repeat percutaneous and endoscopic drainage as well as a cystgastrostomy. During admission for cyst-gastrostomy, the patient developed bilateral sub-massive pulmonary embolism and left popliteal deep venous thrombosis while on warfarin, necessitating placement of an inferior vena cava filter. In addition, the patient reported a remote history of suspected GIB prophylactically treated with coil embolization of the gastroduodenal artery.

One month prior to referral, the patient developed chylous ascites requiring repeat paracentesis. Analysis of ascites demonstrated milky white fluid, with $89 \%$ neutrophils, $11 \%$ mononuclear cells, and a triglyceride level of $1294 \mathrm{mg} / \mathrm{dL}$. CT imaging demonstrated focal splenic and superior mesenteric venous stenoses, gastric varices, splenoportal collaterals, and large abdominal ascites. After discussion with the patient, the decision was made to proceed with percutaneous transhepatic venography with potential venoplasty and stenting.

Under moderate sedation, ultrasound-guided transhepatic right portal access was obtained with a 21 gauge chiba needle. As the procedure involved a transhepatic approach, no intraprocedural heparin was given. Positioning was confirmed with injection of contrast under fluoroscopy. A 0.018 " nitinol (Nitrex) guidewire with a 5 Fr KMP catheter (Cook) was advanced into the portal venous system. Portal venogram was normal, with a pressure of $3 \mathrm{mmHg}$. Superior mesenteric venogram demonstrated stricture adjacent to the portal confluence and an elevated pressure of $9 \mathrm{mmHg}$. Progressive superior mesenteric venoplasty was performed up to $7 \mathrm{~mm}$ with a Armada 35 balloon (Abbott Vascular). No change in the pressure gradient of $6 \mathrm{mmHg}$ was demonstrated.

The splenic vein was then selectively catheterized. To confirm positioning within the splenic vein, the splenic artery was selectively catheterized. Digital subtraction angiogram of the splenic artery revealed delayed opacification surrounding the catheter within the splenic vein. Splenic venogram demonstrated reversal of normal portal venous flow, multiple splenoportal venous collaterals, and a splenic venous pressure of $17 \mathrm{mmHg}$ (Fig. 1). Progressive splenic venoplasty was performed with a Armada 35 balloon (Abbott Vascular) up to $1 \mathrm{~cm}$ with no angiographic or hemodynamic improvement. Two 10 $\mathrm{mm} \times 40 \mathrm{~mm}$ Cordis stents were placed, which resulted in resolution of splenoportal collaterals and a decrease in the pressure gradient to $7 \mathrm{mmHg}$ (Fig. 2). Track embolization was performed using two $8 \mathrm{~mm} \times 14 \mathrm{~cm}$ coils and gelfoam slurry. He was maintained on a heparin drip for 1 week before transitioning to $5 \mathrm{mg}$ of apixaban twice daily. The patient developed a postprocedure perihepatic hematoma but was discharged shortly thereafter, having received no additional interventions. He remained free of ascites 6 months after the procedure.

\section{Discussion}

Splenic vein stenosis most commonly occurs as a sequela of pancreatic disease (Luo et al. 2014; Stein and

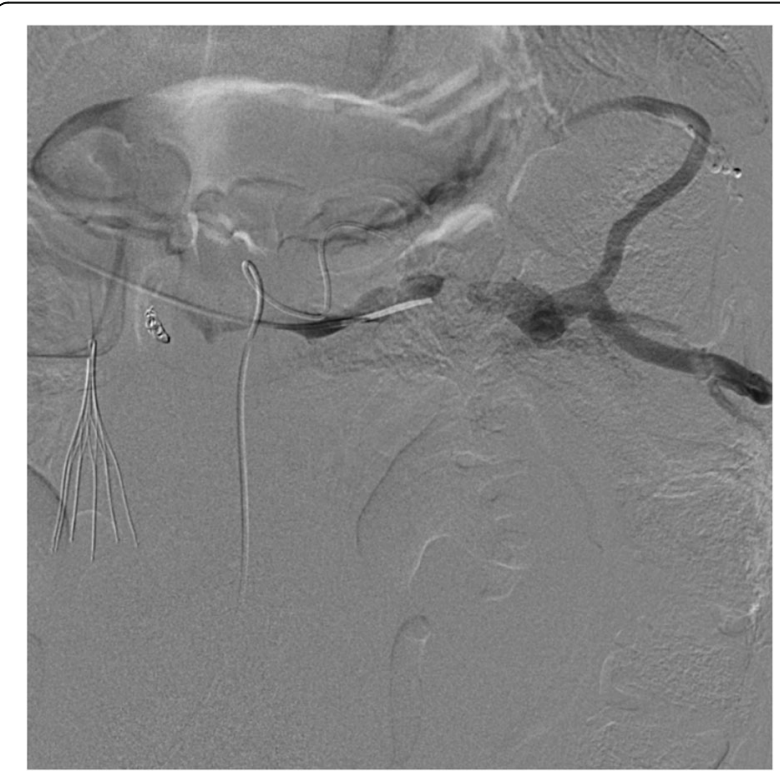

Fig. 1 Digital subtraction venography of the splenic vein prior to venoplasty reveals multiple areas of stenosis and robust venous collaterals from portal hypertension 


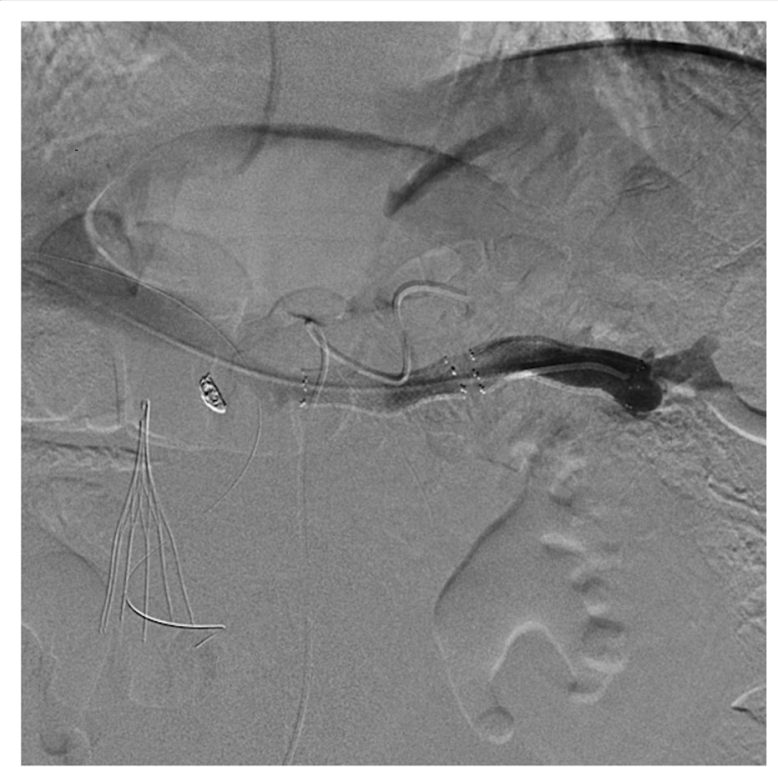

Fig. 2 Digital subtraction venography of the splenic vein after deployment of splenic stents shows increased splenic venous patency with resolution of splenoportal collaterals

Link 1999). The patient's history of pancreatitis with infected pseudocyst was the likely etiology of splenic venous stenosis. The most common clinical presentation of $\mathrm{SPH}$ is GIB, and most cases of splenic vein recanalization have treated this presentation (Fernandes et al. 2015). Several case reports have shown successful treatment of chylous ascites with portal venous stenting (PVS) (Tsauo et al. 2016; Poo et al. 2018; Maleux et al. 2003).

Splenectomy is the historical treatment of SPH-related GIB, although SVS and SAE have been advocated as possible life-saving alternatives (Wei et al. 2020; Fernandes et al. 2015). Post-splenectomy sepsis from asplenia carries a reported mortality rate as high as 6\% (Loftus et al. 1993). Rebleeding rates as high as 16\% have been reported (Loftus et al. 1993). SAE carries the risk of splenic abscess, post-infarction syndrome, and incomplete therapeutic response requiring splenectomy (Fernandes et al. 2015).

Luo et al. (2014) published a report on 11 patients diagnosed with SPH-related GIB who underwent transjugular splenic vein recanalization. Six of these patients were identified as having splenic vein stenosis, and technical success was achieved in each case (Luo et al. 2014). A recent retrospective comparative study between SAE and SVS for SPH-related GIB showed patients treated with SVS were less likely to develop rebleeding, with rebleeding rates of $7.1 \%$ and $47.8 \%$ in SVS versus SAE groups respectively (Wei et al. 2020). The literature regarding SVS for SPH-related ascites is less robust, with few studies describing treatment with PVS rather than
SVS (Tsauo et al. 2016; Poo et al. 2018; Maleux et al. 2003; Stein and Link 1999).

$\mathrm{SPH}$-related chylous ascites is caused by redistribution of gastrointestinal lymphatic flow from increased portosystemic venous pressure (Tsauo et al. 2016). In 2003, Maleux et al. first reported successful treatment of chylous ascites from portal vein stenosis with PVS, attaining resolution of chylous ascites at 1-year follow-up (Maleux et al. 2003). Stein and Link (1999) studied 21 patients with either portal vein, splenic vein, or combined portal and splenic vein stenosis. Fifteen of their patients presented with GIB, and 2 presented with intractable ascites; however, the treatment approach for patients with ascites was not specified (Stein and Link 1999). Lastly, Poo et al. (2018) reported a patient with chylous ascites who had a tight focal stenosis involving the SMV and main portal vein. The patient was treated with PVS and was ascites-free at 1-year follow-up (Poo et al. 2018). Given that the described patient presented with a nonemergent presentation of SPH, SVS was felt to be the safest option in lieu of his multiple comorbidities and preference for minimally-invasive therapy.

While no long-term patency studies of SVS for SPHrelated chylous ascites are reported in the literature, comparisons may be tentatively drawn from splenic vein patency rates in SPH-related GIB. Wei et al. (2020) reported a cumulative stent patency rate of $92.9 \% 12$ months after SVS for SPH-related GIB. A single splenic stent dysfunction was their only SVS-related complication (Wei et al. 2020). Both cases of PVS for chylous ascites in the literature reported portal venous patency at 1 year. Maleux et al. (2003) gave their patient 1 month of daily $40 \mathrm{mg}$ low molecular weight heparin followed by long-term daily $160 \mathrm{mg}$ acetylic salicyclic acid, while Poo et al. (2018) gave their patient long-term $75 \mathrm{mg}$ daily aspirin. The patient in the current case was given 1 week of heparin drip while hospitalized, followed by his preprocedural anticoagulation of $5 \mathrm{mg}$ apixaban twice daily. Anticoagulation regimen was determined based upon the patient's history of atrial fibrillation, rather than maintenance of splenic stent patency and likely would have consisted of a less aggressive regimen in the absence of this history. There are no standardized guidelines regarding anticoagulation after portomesenteric stenting, and some studies have failed to find an association between type of anticoagulation and risk of stent thrombosis (Sheth et al. 2018). At 6 months follow-up, the patient remained free of abdominal ascites.

There has been some debate in the literature regarding a transjugular versus transhepatic approach, with some interventionalists avoiding a transhepatic approach due to the perceived risk of increased bleeding (Luo et al. 2014). Studies have shown success via both approaches, and a transhepatic approach was taken in the current 
case due to the relative ease of the technique and the patient's stable bloodwork (El Kininy et al. 2017; Ghelfi et al. 2016; Luo et al. 2014; Stein and Link 1999). Nevertheless, the development of a perihepatic hematoma in the current case exemplifies the importance of weighing a variety of factors when planning an approach.

\section{Conclusions}

This case report highlights successful treatment of SPHrelated recurrent chylous ascites with transhepatic SVS. While evidence for SVS for SPH-related chylous ascites remains sparse, technical success and resolution of ascites suggest that splenic vein recanalization may be a safe and viable option. Although the current literature is promising, additional scientific studies are needed to assess the role of SVS for other SPH-related symptomatology.

\section{Acknowledgements}

Not applicable.

\section{Authors' contributions}

All authors made substantial contributions to the conception of the work. BC drafted the manuscript. JM and RF substantially revised the manuscript. All authors have approved the submitted version and agree to be personally accountable for the author's own contributions. All authors ensure the integrity of this work.

Authors' information

Not applicable.

Funding

This study was not supported by any funding.

Availability of data and materials

All data generated or analyzed during this study are included in this published article.

\section{Declarations}

\section{Ethics approval and consent to participate}

All procedures performed in studies involving human participants were in accordance with the ethical standards of the institutional and/or national research committee and with the 1964 Helsinki declaration and its later amendments or comparable ethical standards. IRB approval was not required by our institution for this case report per HCA Healthcare ethics committee.

\section{Consent for publication}

Written informed consent was obtained from the patient for publication of this case report and any accompanying images.

\section{Competing interests}

All authors have no competing interests to disclose.

Received: 5 February 2021 Accepted: 23 February 2021

Published online: 03 March 2021

\section{References}

El Kininy W, Kearney L, Hosam N, Broe P, Keeling A (2017) Recurrent variceal haemorrhage managed with splenic vein stenting. Ir J Med Sci 186(2):323327. https://doi.org/10.1007/s11845-016-1420-z

Fernandes A, Almeida N, Ferreira AM et al (2015) Left-sided portal hypertension: a sinister entity. GE Port J Gastroenterol 22(6):234-239. https://doi.org/10.1016/ j.jpge.2015.09.006

Ghelfi J, Thony F, Frandon J, Rodiere M, Leroy V, Vendrell A (2016) Gastrointestinal bleeding due to pancreatitis-induced splenic vein thrombosis: treatment with percutaneous splenic vein recanalization. Diagn Interv Imaging 97(6):677-679. https://doi.org/10.1016/.diii.2016.01.005

Loftus JP, Nagorney DM, Ilstrup D, Kunselman AR (1993) Sinistral portal hypertension. Splenectomy or expectant management. Ann Surg 217(1):3540. https://doi.org/10.1097/00000658-199301000-00007

Luo X, Nie L, Wang Z, Tsauo J, Tang C, Li X (2014) Transjugular endovascular recanalization of splenic vein in patients with regional portal hypertension complicated by gastrointestinal bleeding. Cardiovasc Intervent Radiol 37(1): 108-113. https://doi.org/10.1007/s00270-013-0625-z

Maleux G, Vaninbroukx J, Verslype C, Vanbeckevoort D, Van Hootegem P, Nevens F (2003) Pancreatitis-induced extrahepatic portal vein stenosis treated by percutaneous transhepatic stent placement. Cardiovasc Intervent Radiol 26(4):395-397. https://doi.org/10.1007/s00270-003-0026-9

Poo S, Pencavel TD, Jackson J, Jiao LR (2018) Portal hypertension and chylous ascites complicating acute pancreatitis: the therapeutic value of portal vein stenting. Ann R Coll Surg Engl 100(1):e1-e3. https://doi.org/10.1308/rcsann.2 017.0078

Sheth RA, Sabir SH, Parmet P et al (2018) Portomesenteric venous stenting for palliation of ascites and Variceal bleeding caused by Prehepatic portal hypertension. Oncologist 23(6):712-718. https://doi.org/10.1634/ theoncologist.2017-0337

Stein M, Link DP (1999) Symptomatic spleno-mesenteric-portal venous thrombosis: recanalization and reconstruction with endovascular stents. J Vasc Interv Radiol 10(3):363-371. https://doi.org/10.1016/s1051-0443 (99)70044-8

Tsauo J, Shin JH, Han K et al (2016) Transjugular intrahepatic Portosystemic shunt for the treatment of Chylothorax and Chylous ascites in cirrhosis: a case report and systematic review of the literature. J Vasc Interv Radiol 27(1):112116. https://doi.org/10.1016/j.jvir.2015.09.022

Wei B, Zhang L, Tong H, Wang Z, Wu H (2020) Retrospective comparison of clinical outcomes following splenic vein stenting and splenic arterial embolization in Sinistral portal hypertension-related gastrointestinal bleeding. AJR am J Roentgenol. https://doi.org/10.2214/AJR.20.23859

\section{Publisher's Note}

Springer Nature remains neutral with regard to jurisdictional claims in published maps and institutional affiliations.

\section{Submit your manuscript to a SpringerOpen ${ }^{\circ}$ journal and benefit from:}

- Convenient online submission

- Rigorous peer review

- Open access: articles freely available online

- High visibility within the field

- Retaining the copyright to your article

Submit your next manuscript at $\boldsymbol{\nabla}$ springeropen.com 